\title{
Mulching Measures Improve Soil Moisture in Rain-Fed Jujube (Ziziphus jujuba Mill.) Orchards in the Loess Hilly Region of China
}

\author{
Min Tang ${ }^{1,2}$, Hongchen $\mathrm{Li}^{3}$, Chao Zhang ${ }^{1, *}$, Xining Zhao ${ }^{2, *}$, Xiaodong Gao ${ }^{2}$ and Pute $\mathrm{Wu}^{2}$ \\ 1 College of Hydraulic Science and Engineering, Yangzhou University, Yangzhou 225009, China; \\ 007312@yzu.edu.cn \\ 2 Institute of Water-saving Agriculture in Arid Areas of China, Northwest Agriculture and Forestry University, \\ Yangling 712100, China; gao_xiaodong@nwafu.edu.cn (X.G.); gjzwpt@vip.sina.com (P.W.) \\ 3 School of Resources and Environmental Engineering, Ludong University, Yantai 264025, China; \\ lihc@ldu.edu.cn \\ * Correspondence: zhangc1700@yzu.edu.cn (C.Z.); zxn@nwsuaf.edu.cn (X.Z.)
}

Citation: Tang, M.; Li, H.; Zhang, C.; Zhao, X.; Gao, X.; Wu, P. Mulching Measures Improve Soil Moisture in Rain-Fed Jujube (Ziziphus jujuba Mill.) Orchards in the Loess Hilly Region of China. Sustainability 2021, 13, 610. https://doi.org/10.3390/su13020000

Received: 23 November 2020 Accepted: 5 January 2021

Published: 11 January 2021

Publisher's Note: MDPI stays neutral with regard to jurisdictional clai$\mathrm{ms}$ in published maps and institutional affiliations.

Copyright: $\odot 2021$ by the authors. Licensee MDPI, Basel, Switzerland. This article is an open access article distributed under the terms and conditions of the Creative Commons Attribution (CC BY) license (https:// creativecommons.org/licenses/by/ $4.0 /)$.

\begin{abstract}
Water shortage is the main bottleneck restricting the sustainable development of rain-fed jujube (Ziziphus jujuba Mill.) orchards in the loess hilly region of China. Given the effect of mulching on soil moisture conservation, straw mulching (SM) and jujube branch mulching (BM) were applied to a rain-fed jujube orchard in this study. Soil moisture dynamics, soil water storage, water consumption, and soil moisture attenuation after typical rainfall under $\mathrm{SM}, \mathrm{BM}$, and clean tillage (CT) were studied. The results showed the following: (1) The $0-60 \mathrm{~cm}$ soil layer was the seasonal fluctuation layer of soil moisture under SM, BM, and CT in both the normal precipitation year and the dry year studied. The moisture contents of the $0-60,60-160$, and 160-280 cm soil layers under SM and BM were higher than that under $\mathrm{CT}$ in the three experimental years studied, and SM showed the most obvious effect of increasing soil moisture. (2) SM and BM showed a significant soil water storage effect in all of the jujube growth stages, and SM had a better water storage effect than BM. (3) SM reduced the amount of water consumption by $94.3,60.8$, and $121.3 \mathrm{~mm}$ compared to $\mathrm{CT}$ in the whole jujube growth period in 2014, 2015, and 2016, respectively. The amount of water consumption of BM decreased by 34.8 and $31.0 \mathrm{~mm}$ compared to that of $\mathrm{CT}$ in the whole growth period in 2014 and 2015, respectively. (4) CT had the maximum soil moisture loss rate under continuous drought after rainfall. The soil moisture loss rate of CT was above $37.3 \%$ on the eleventh day after typical rainfall in 2014, 2015, and 2016. With the extension of drought, the soil moisture loss rate under SM increased slowly. This study suggests that SM is the best mulching measure for rain-fed jujube orchards, and pruned jujube branches can also be used for in situ mulching to obtain a certain moisture conservation effect.
\end{abstract}

Keywords: soil moisture; water consumption; continuous drought; mulching; jujube

\section{Introduction}

The loess hilly region of China is characterized by a dry climate, strong evaporation, scarce precipitation and uneven seasonal distribution, and a mismatch between natural precipitation and crop water demand [1,2]. The topography of the loess hilly region is dominated by sloping land, much of which has a great gradient and a loose soil structure, resulting in serious soil erosion [3,4]. In addition, there is little irrigation in the loess hilly region, and most of the crop growth depends on natural precipitation $[5,6]$. Water shortage severely restricts the development of agriculture and forestry in the loess hilly region [7]. How to reasonably and efficiently utilize the limited natural precipitation in the loess hilly region has now become the main focus and trend.

As the main economic and ecological forest for soil and water conservation in the loess hilly region, the jujube (Ziziphus jujuba Mill.) cultivation area has expanded rapidly in recent years, and it has exceeded one million hectares [8,9]. Clean tillage, that is, weeding multiple 
times during the crop growing season, is currently widely used in jujube orchards [10]. Clean tillage has the advantages of pest control and seedling raising for orchards, with good short-term effects. However, many studies have found that long-term clean tillage causes serious soil erosion, a decline in soil fertility, deterioration of soil properties, and the destruction of ecological balance, and ultimately leads to the premature aging of fruit trees, a reduction in fruit yield, and a deterioration of fruit quality, which is not conducive to the sustainable development of orchards [11-13].

As an effective soil management measure in rain-fed areas, mulching has been recognized and widely used in many countries. Mulching has the functions of conserving soil moisture, reducing evaporation, improving soil fertility, adjusting soil temperature, etc., which are beneficial to promoting crop growth and water-use efficiency [14]. At present, several researchers have applied mulching measures (straw, plastic film, organic matter, gravel, pruned branches, gramineous and leguminous grass, rape cultivation, etc.) to rain-fed peach, apricot, olive, apple, jujube, pomegranate, and fig orchards [15-21]. Such researchers have found that appropriate mulching measures can effectively promote rainfall infiltration, weaken soil erosion, increase soil moisture, reduce soil evaporation, improve soil properties, enhance soil fertility, regulate soil temperature, stimulate soil microbial activity, have a positive impact on fruit tree growth, fruit yield and quality, and improve water-use efficiency.

Based on the above-mentioned background, maize straw and pruned jujube branches were used to cover the soil surface of a rain-fed jujube orchard in the loess hilly region, and the impact of these two mulching measures on soil moisture was studied. The findings can provide a scientific basis for the selection and promotion of mulching measures, the efficient utilization of precipitation resources, and the sustainable development of rain-fed jujube orchards in the loess hilly region.

\section{Materials and Methods}

\subsection{Study Site}

The experiment was conducted at the Jujube Demonstration Bases $\left(37^{\circ} 15^{\prime} \mathrm{N}, 110^{\circ} 21^{\prime} \mathrm{E}\right)$ in Dianzegou Town, Qingjian County, Yulin City, Shaanxi Province, China (Figure 1a), which is located in the loess hilly region. The climate of the study site is a warm temperate continental monsoon semi-arid climate, with an annual average precipitation of $505 \mathrm{~mm}$, of which the precipitation from June to August accounts for approximately $80 \%$ of the total annual precipitation (Figure 1c). The annual average air temperature at the study site is $9.6^{\circ} \mathrm{C}$, with an average air temperature of $-6.8^{\circ} \mathrm{C}$ in January and $23.8^{\circ} \mathrm{C}$ in July (Figure 1c). Both the air temperature difference between day and night and the air temperature change in seasons is great. The study site has abundant sunshine, with an annual average sunshine duration of $2720 \mathrm{~h}$ and a frost-free period of 160-170 days.

As shown in Figure 2, the precipitation was 373.6, 258.8, and $344.4 \mathrm{~mm}$ during the jujube growth period (early May to mid-October) in 2014, 2015, and 2016. According to Hao et al. [22], a year when the precipitation increases or decreases within $10 \%$ of the annual average precipitation during the crop growth period is a normal precipitation year, and a year when the precipitation decreases by more than $10 \%$ of the annual average precipitation during the crop growth period is a dry year. Therefore, 2014 and 2016 were classified as normal precipitation years, and 2015 was a dry year. The soil at the study site is loessal soil, belonging to silt loam, with a loose structure and a strong infiltration capacity. The main physical properties of the $0-180 \mathrm{~cm}$ soil layer at the study site are shown in Table 1. 


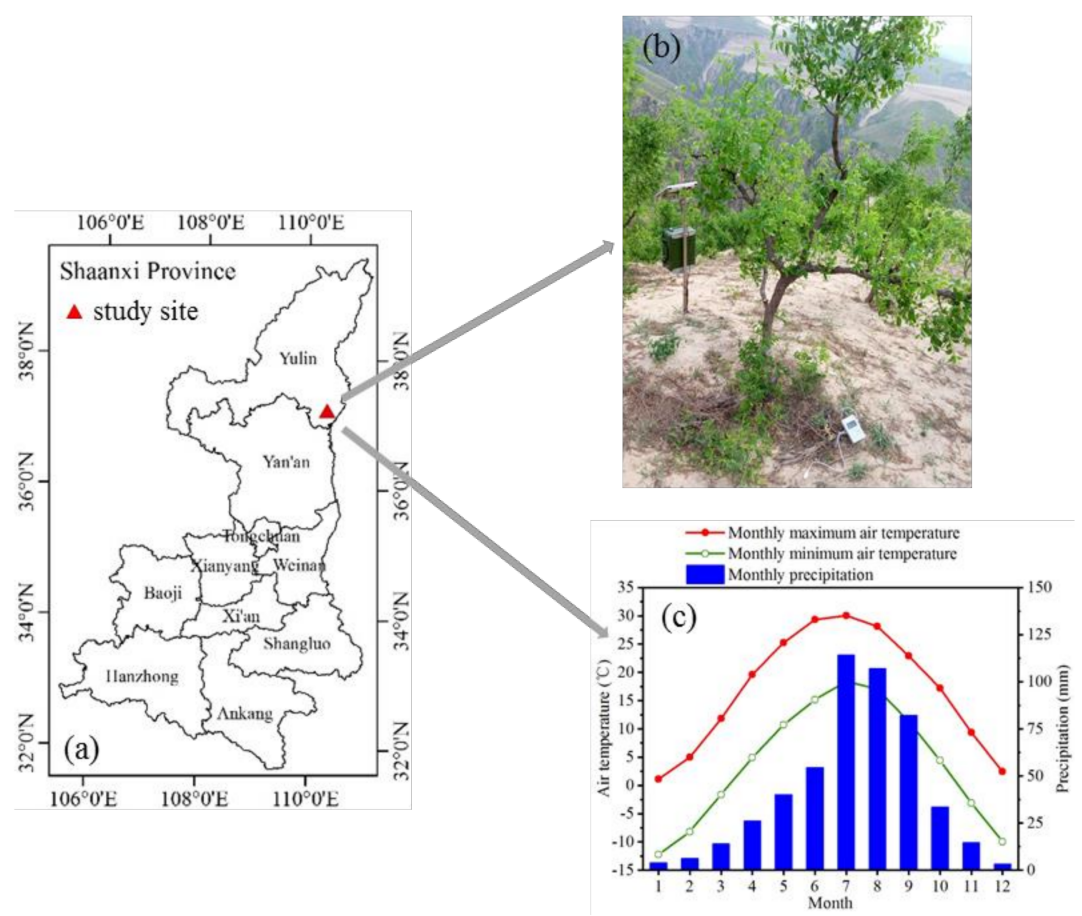

Figure 1. General situation of the study site: (a) geographical location, (b) experimental jujube orchard, and (c) climate background. Air temperature and precipitation data were obtained from the statistical data released by the National Meteorological Center of China Meteorological Administration (http:/ / www.nmc.cn/publish/forecast/ASN/qingjian.html).

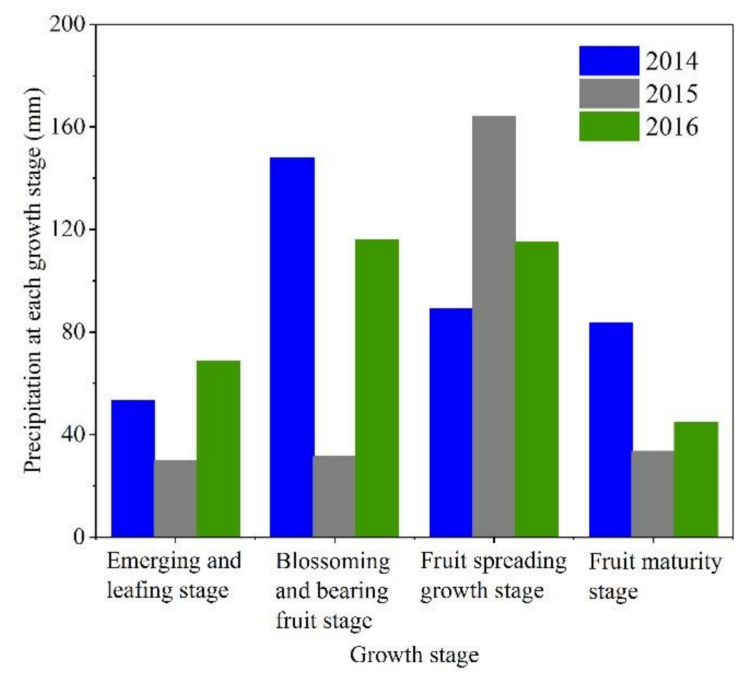

Figure 2. Precipitation at each growth stage of jujube trees in 2014, 2015, and 2016. 
Table 1. Soil properties of the $0-180 \mathrm{~cm}$ layer at the study site.

\begin{tabular}{|c|c|c|c|c|c|c|c|c|}
\hline \multirow{2}{*}{$\begin{array}{l}\text { Soil Layer } \\
\text { (cm) }\end{array}$} & \multirow{2}{*}{$\begin{array}{c}\text { Bulk } \\
\text { Density } \\
\left(\mathrm{g} \cdot \mathrm{cm}^{-3}\right)\end{array}$} & \multicolumn{3}{|c|}{ Soil Particle Composition ${ }^{\text {a }}$} & \multirow{2}{*}{$\begin{array}{c}K_{\text {sat }} b \\
\left(\mathrm{~mm} \cdot \mathrm{min}^{-1}\right)\end{array}$} & \multirow{2}{*}{$\begin{array}{c}\theta_{\mathrm{s}} \mathrm{c} \\
\left(\mathrm{cm}^{3} \cdot \mathrm{cm}^{-3}\right)\end{array}$} & \multirow{2}{*}{$\begin{array}{c}\theta_{33 \mathrm{kPa}}{ }^{\mathrm{d}} \\
\left(\mathrm{cm}^{3} \cdot \mathrm{cm}^{-3}\right)\end{array}$} & \multirow{2}{*}{$\begin{array}{l}\theta_{1500 \mathrm{kPa}}{ }^{\mathrm{e}} \\
\left(\mathrm{cm}^{3} \cdot \mathrm{cm}^{-3}\right)\end{array}$} \\
\hline & & Sand $(\%)$ & Silt (\%) & Clay (\%) & & & & \\
\hline $0-20$ & 1.27 & 19.1 & 64.7 & 16.2 & 1.21 & 50.4 & 27.5 & 6.6 \\
\hline $20-40$ & 1.31 & 18.8 & 64.8 & 16.4 & 1.28 & 50.8 & 27.1 & 7.2 \\
\hline $40-60$ & 1.31 & 17.9 & 63.1 & 19.0 & 1.16 & 53.1 & 28.4 & 7.1 \\
\hline $60-80$ & 1.45 & 17.4 & 64.5 & 18.1 & 0.91 & 52.8 & 28.1 & 7.3 \\
\hline $80-100$ & 1.37 & 18.7 & 62.8 & 18.5 & 0.85 & 52.3 & 27.8 & 8.1 \\
\hline $100-120$ & 1.40 & 16.5 & 62.5 & 21.0 & 0.82 & 57.1 & 30.4 & 9.5 \\
\hline $120-140$ & 1.37 & 16.1 & 63.2 & 20.7 & 0.92 & 55.8 & 30.2 & 9.2 \\
\hline $140-160$ & 1.41 & 16.8 & 62.9 & 20.3 & 0.86 & 56.4 & 29.0 & 7.9 \\
\hline $160-180$ & 1.46 & 16.2 & 64.1 & 19.7 & 0.94 & 55.4 & 29.2 & 8.8 \\
\hline
\end{tabular}

a Soil particle composition: sand $\%$ (2-0.02 mm), silt $\%(0.02-0.002 \mathrm{~mm})$, and clay $\%(<0.002 \mathrm{~mm}) ;{ }^{\mathrm{b}} \mathrm{K}_{\mathrm{sat}}$ : Saturated hydraulic conductivity;

${ }^{\mathrm{c}} \theta_{\mathrm{s}}$ : Saturated moisture; ${ }^{\mathrm{d}} \theta_{33 \mathrm{kPa}}$ : Soil moisture content at $33 \mathrm{kPa}$; ${ }^{\mathrm{e}} \theta_{1500 \mathrm{kPa}}$ : Soil moisture content at $1500 \mathrm{kPa}$.

\subsection{Experimental Design}

A jujube orchard with a slope gradient of $20^{\circ}$ and a south slope direction was selected as the experimental plot (Figure 1b). The jujube variety was Lizao, which was planted in 2003 and was in the full bearing period during the experiment. According to jujube's growth characteristics, the jujube growth period was divided into four stages, namely, the emerging and leafing stage (early May to mid-June), the blossoming and bearing fruit stage (mid-June to mid-July), the fruit spreading growth stage (mid-July to mid-September), and the fruit maturity stage (mid-September to mid-October). The plant and row spacing of jujube trees were 2 and $3 \mathrm{~m}$, respectively. A small amount of farmyard manure and $0.3 \mathrm{~kg}$ per plant of urea were applied to the experimental jujube orchard at the beginning of each year. The jujube trees were pruned to a height of approximately $2 \mathrm{~m}$ in April every year, and the jujube orchard was regularly weeded manually. The jujube orchard was managed under rain-fed conditions without irrigation during the experiment.

Three treatments were designed, namely, straw mulching (SM), jujube branch mulching (BM), and clean tillage (CT). Each treatment was repeated twice, with a total of six experimental plots, which were completed in March 2013. The mulching material of SM was maize straw, the mulching thickness was $15 \mathrm{~cm}$, and maize straw was supplemented at the end of the jujube growth period every year to ensure the designed mulching thickness. The pruned jujube branches were broken to $10 \mathrm{~cm}$ in length under $\mathrm{BM}$, and the mulching thickness was also $10 \mathrm{~cm}$. The soil surface under CT was exposed without any mulching measures.

\subsection{Soil Moisture and Precipitation Measurement}

An automatic soil moisture measuring device was installed in each experimental plot in late April 2014. The soil volumetric moisture content was measured using an EC-5 soil moisture sensor (Decagon Devices Inc., Pullman, WA, USA) at a frequency of $10 \mathrm{~min}$. The monitor point was $30 \mathrm{~cm}$ away from the jujube trunk. Given that $90 \%$ of the fine roots of jujube trees are concentrated in the $0-300 \mathrm{~cm}$ soil layer [23], the observation depth of the soil moisture was 10, 20, 40, 60, 100, 160, 220, and $280 \mathrm{~cm}$ (Figure 3). For two plots with the same experimental treatment, their soil moisture content at the same depth was averaged. The precipitation data in the study area were collected by an AR- 5 automatic weather station (Avolon Scientific, Inc., Jersey City, USA) approximately $100 \mathrm{~m}$ away from the experimental jujube orchard. 


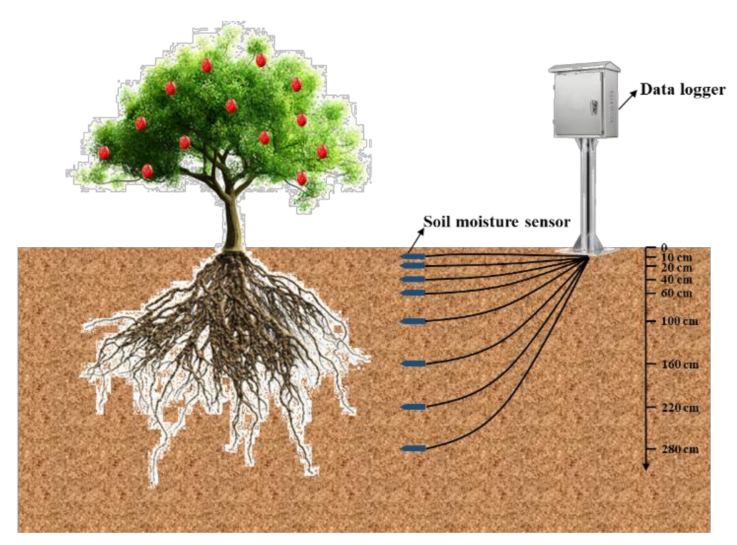

Figure 3. Schematic diagram of soil moisture sensor layout.

\subsection{Data Analysis}

Soil water storage $(W, \mathrm{~mm})$ was calculated using the following formula [24]:

$$
W=\sum_{i=1}^{n}\left(\theta_{i} \times h_{i}\right)
$$

where $n$ represents the number of soil layers, $\theta_{i}$ is the volumetric moisture content of the $i$-th soil layer $\left(\mathrm{cm}^{3} \cdot \mathrm{cm}^{-3}\right)$, and $h_{i}$ is the thickness of the $i$-th soil layer $(\mathrm{mm})$.

For rain-fed fields, the crop water consumption is the crop water requirement, that is, the evapotranspiration $(E T, \mathrm{~mm})$, including crop transpiration $(T, \mathrm{~mm})$ and soil evaporation $(E, \mathrm{~mm})$, which can be calculated using the soil water balance equation [25]:

$$
E T=P+I+U-R-D-I N-\Delta W
$$

where $P$ represents the precipitation $(\mathrm{mm}), I$ is the irrigation $(\mathrm{mm}), U$ is the groundwater recharge $(\mathrm{mm}), R$ is the surface runoff $(\mathrm{mm}), D$ is the deep percolation $(\mathrm{mm}), I N$ is the interception of precipitation by plant canopy, and $\Delta W$ is the change of soil water storage, defined as the difference between the soil water storage measured at the beginning and the end of the calculation period ( $\mathrm{mm})$.

The experimental jujube orchard was rain-fed without irrigation, so $I=0$. The buried depth of the groundwater in the study area exceeds $50 \mathrm{~m}$, so it can be considered that $U=0$ [23]. The study area has a deep soil layer and strong water storage capacity, so storedfull runoff rarely occurs. For a runoff yield in excess of the infiltration caused by heavy rain, wide horizontal steps were built in the experimental jujube orchard, which can reduce the runoff outflow from the jujube orchard, so it can be considered that $R=0$. Han et al. [26] found that the soil water storage capacity of the Loess Plateau is $200-250 \mathrm{~mm} \cdot \mathrm{m}^{-1}$, and the soil can still hold approximately $100 \mathrm{~mm} \cdot \mathrm{m}^{-1}$ of water after it has accumulated some water. This study focused on the $0-280 \mathrm{~cm}$ soil layer, which can store approximately $280 \mathrm{~mm}$ of precipitation, which is much higher than the maximum precipitation in the study area, so deep percolation will not occur after rainfall, that is, $D=0$. The jujube trees were pruned every April, and the invalid rainfall with daily rainfall less than $5 \mathrm{~mm}$ was ignored when the effective rainfall was counted, so the canopy interception can be considered negligible, that is, $I N=0$. The calculation equation of ET can be simplified as:

$$
E T=P-\Delta W
$$

The water consumption percentage $(C P)$ was obtained according to Huang et al. [27] as follows:

$$
C P=W C_{i} / W C_{T} \times 100 \%
$$


where $W C_{i}$ represents the water consumption of the jujube trees in the $i$-th growth stage $(\mathrm{mm})$, and $W C_{T}$ is the total water consumption in all growth stages $(\mathrm{mm})$.

The soil moisture loss rate $(S M L R)$ was estimated from the following equation [28]:

$$
S M L R=\frac{S M C_{1}-S M C_{n+1}}{S M C_{1}} \times 100 \%
$$

where $S M C_{1}$ represents the soil volumetric moisture content on the first day after rainfall, and $S M C_{n+1}$ represents the soil volumetric moisture content on the $(n+1)$-th day after rainfall.

Statistical analysis was performed using Microsoft Excel 2013 (Microsoft, Redmond, WA, USA) and SPSS 20.0 (IBM Corp., Armonk, NY, USA). An independent samples $t$-test was conducted to compare the differences in soil moisture in the same soil layer under different experimental treatments. Differences were considered statistically significant when $p<0.05$. The software OriginPro 2017 (OriginLab, Northampton, MA, USA) was used for making figures.

\section{Results}

3.1. Soil Moisture Dynamics in the Rain-Fed Jujube Orchard under Different Mulching Measures

According to the distribution characteristics of the fine roots of the jujube trees, the soil profile was divided into a fine root dense layer $(0-60 \mathrm{~cm})$, a fine root diffuse layer $(60-160 \mathrm{~cm})$, and a fine root sparse layer $(160-280 \mathrm{~cm})$. The soil moisture changes in the three soil layers of the jujube orchard under different mulching measures were almost consistent in three experimental years (Figure 4). Due to the influence of rainfall and evaporation, the soil moisture in the fine root dense layer fluctuated violently, which belonged to the seasonal fluctuation layer (Figure 4a). The soil moisture in this soil layer increased rapidly after effective rainfall, and then decreased with continuous drought. CT obtained the lowest soil moisture content in the three growing seasons. Particularly in multiple periods of the fruit spreading growth stage in the dry year (2015), the soil moisture content was even lower than the wilting moisture $(7 \%)$. Although the rainfall at each growth stage in 2016 was significantly higher than that in the same period in 2015, the air temperature in the blossoming and bearing fruit stage, the fruit spreading growth stage, and the fruit maturity stage in 2016 was $0.21,0.44$, and $1.64{ }^{\circ} \mathrm{C}$ higher than that in the same period in 2015, respectively, which led to an increase in soil evaporation, resulting in the soil moisture content in the fine root dense layer under CT being continuously lower than the wilting moisture from the blossoming and bearing fruit stage to the fruit maturity stage in 2016, which resulted in the formation of a seasonal low-humidity zone. The soil moisture content in the fine root dense layer under SM increased by $5.68 \%, 4.60 \%$, and $4.41 \%$ in the growing seasons of 2014, 2015, and 2016, respectively, compared to CT $(p<0.05)$. The soil moisture content in the fine root dense layer under BM increased by $4.41 \%, 3.24 \%$, and $3.27 \%$ in the growing seasons of 2014, 2015, and 2016, respectively, compared to CT $(p<0.05)$.

The soil moisture content of the fine root diffuse layer was mainly affected by the distribution density of fine roots and was weakly affected by rainfall (Figure $4 \mathrm{~b}$ ). SM had the highest soil moisture content with $16.38 \%, 15.04 \%$, and $14.25 \%$ in the growing seasons of 2014, 2015, and 2016, respectively. The soil moisture content under BM increased by $2.77 \%, 2.09 \%$, and $1.43 \%$ compared to CT in the growing seasons of 2014, 2015, and 2016, respectively $(p<0.05)$. The soil moisture in the fine root sparse layer was hardly affected by rainfall (Figure $4 \mathrm{c}$ ). The soil moisture content of the fine root sparse layer under CT was lower than the wilting moisture in the three growing seasons, forming a perennial low-humidity zone. The soil moisture content of the fine root sparse layer under the mulching treatments (SM and BM) increased by $6.11-7.80 \%$ compared to CT $(p<0.05)$. 


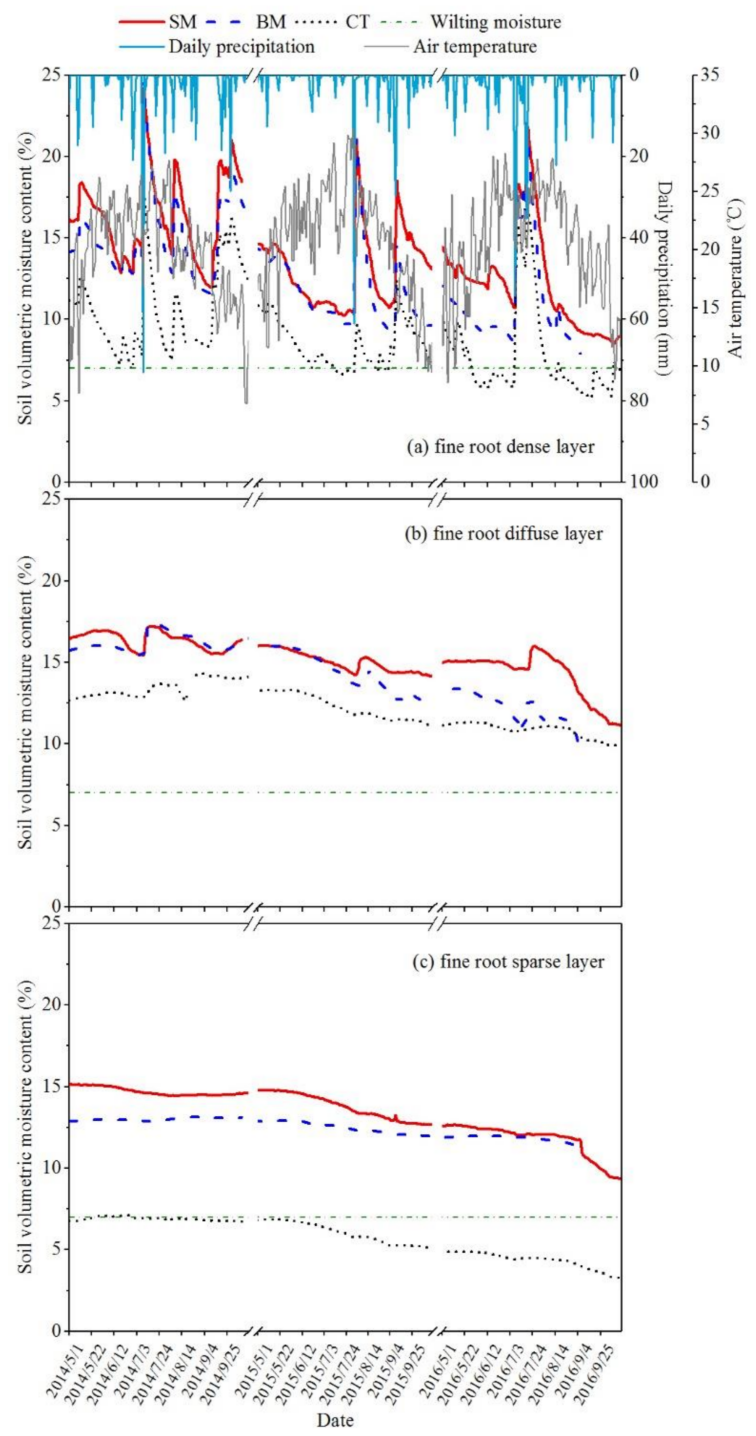

Figure 4. Daily average soil volumetric moisture content changes in (a) the fine root dense layer, (b) the fine root diffuse layer, and (c) the fine root sparse layer under different mulching treatments during the jujube growth period in 2014, 2015, and 2016. SM, straw mulching; BM, jujube branch mulching; CT, clean tillage.

\subsection{Soil Water Storage of the Rain-Fed Jujube Orchard under Different Mulching Measures}

The mulching treatments (SM and BM) showed the obvious effect of increasing the soil moisture at each growth stage, both in the normal precipitation years and the dry year (Figure 5). In the emerging and leafing stages, the water storage of the $0-280 \mathrm{~cm}$ soil layer under SM and BM was 158.8 and $148.5 \mathrm{~mm}$ higher in 2014, 144.3 and $119.4 \mathrm{~mm}$ higher in 2015, and 153.5 and $130.7 \mathrm{~mm}$ higher in 2016 than that under CT, respectively. In the blossoming and bearing fruit stage, the soil water storage of SM and BM was 160.7 and $139.7 \mathrm{~mm}$ in 2014, 138.7 and $119.5 \mathrm{~mm}$ in 2015, and 155.9 and $121.5 \mathrm{~mm}$ in 2016, respectively, higher than that of CT. In the fruit spreading growth stage, the soil water storage under SM and BM was $54.6 \%$ and $49.5 \%$ in $2014,58.0 \%$ and $56.9 \%$ in 2015 , and $68.5 \%$ and $55.9 \%$ in 2016, respectively, higher than that under CT. In the fruit maturity stage, the soil water storage of SM and BM was $41.5 \%$ and $38.9 \%$ higher than that of CT in 2014 , and $60.4 \%$ and $49.0 \%$ higher than that of CT in 2015 (Figure 5a,b). Soil water storage under SM was still $105.4 \mathrm{~mm}$ higher than that under CT in 2016 (Figure 5c). The effect of SM on increasing moisture at each growth stage was better than that of BM in three experimental years. 


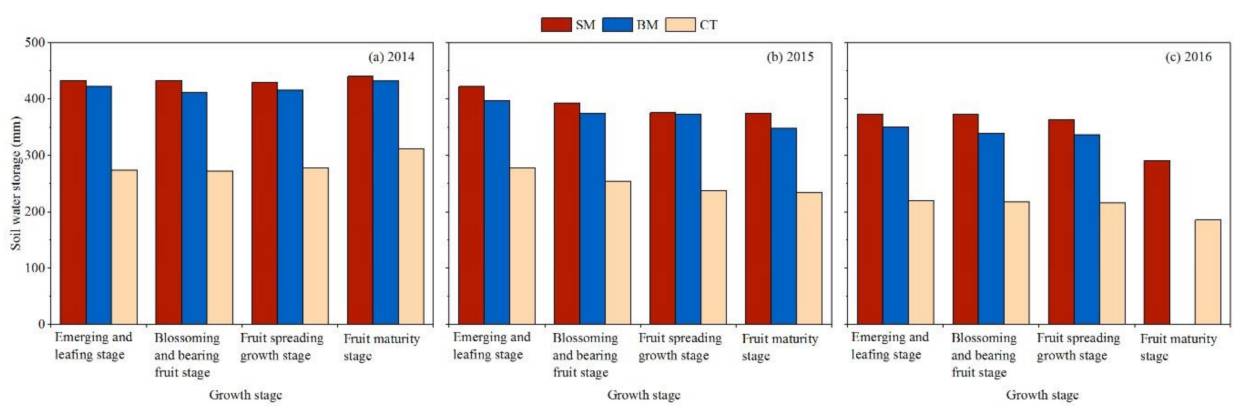

Figure 5. Soil water storage of the $0-280 \mathrm{~cm}$ soil layer under different mulching treatments in the different jujube growth stages in (a) 2014, (b) 2015, and (c) 2016. Due to the malfunction of the soil moisture measuring device under the BM treatment in the 2016 fruit maturity stage, the collected soil moisture data were incorrect, and the soil water storage under the BM treatment could not be calculated in this period.

In the growing season of 2014, the water storage of the $0-280 \mathrm{~cm}$ soil layer under all experimental treatments gradually decreased from the emerging and leafing stage to the blossoming and bearing fruit stage, and then gradually increased due to the supplement of a large amount of rainfall during the fruit spreading growth and fruit maturity stages (Figure 5a). In the growing seasons of 2015 and 2016, the soil water storage of each experimental treatment showed a decreasing trend as the growth stage progressed (Figure 5b,c).

\subsection{Amount and Percentage of the Water Consumption of Jujube Trees under Different Mulching Measures}

As shown in Table 2, the different mulching measures had a significant impact on the amount of water consumption of the jujube trees during the whole growth period. SM reduced the amount of water consumption of the jujube trees by $94.3,60.8$, and $121.3 \mathrm{~mm}$ compared to CT in the growth periods of 2014, 2015, and 2016. The amounts of water consumption of the jujube trees under BM were 34.8 and $31.0 \mathrm{~mm}$ lower than those under CT in the growth periods of 2014 and 2015, respectively.

Table 2. Amount (ET) and percentage (CP) of water consumption of the jujube trees under different mulching treatments at each growth stage in 2014, 2015, and 2016.

\begin{tabular}{|c|c|c|c|c|c|c|c|c|}
\hline \multirow[t]{2}{*}{ Year } & \multirow{2}{*}{$\begin{array}{l}\text { Mulching } \\
\text { Treatment }\end{array}$} & \multicolumn{2}{|c|}{$\begin{array}{l}\text { Emerging and } \\
\text { Leafing Stage }\end{array}$} & \multicolumn{2}{|c|}{$\begin{array}{l}\text { Fruit Spreading } \\
\text { Growth Stage }\end{array}$} & \multicolumn{2}{|c|}{$\begin{array}{c}\text { Fruit Maturity } \\
\text { Stage }\end{array}$} & \multirow{2}{*}{$\begin{array}{c}\begin{array}{c}\text { Whole } \\
\text { Growth } \\
\text { Period }\end{array} \\
\text { ET }(\mathrm{mm})\end{array}$} \\
\hline & & $\mathrm{ET}(\mathrm{mm})$ & $\mathrm{CP}(\%)$ & $\mathrm{ET}(\mathrm{mm})$ & СР(\%) & $\mathrm{ET}(\mathrm{mm})$ & $\mathrm{CP}(\%)$ & \\
\hline \multirow{3}{*}{2014} & SM & 60.1 & 19.8 & 92.8 & 30.6 & 52.3 & 17.3 & 302.9 \\
\hline & $\mathrm{BM}$ & 61.9 & 17.1 & 135.1 & 37.3 & 59.5 & 16.4 & 362.4 \\
\hline & $\mathrm{CT}$ & 62.8 & 15.8 & 144.7 & 36.4 & 80.1 & 20.2 & 397.2 \\
\hline \multirow{3}{*}{2015} & SM & 51.6 & 22.5 & 80.4 & 35.0 & 52.2 & 22.7 & 229.7 \\
\hline & $\mathrm{BM}$ & 53.7 & 20.7 & 101.7 & 39.2 & 55.2 & 21.3 & 259.4 \\
\hline & $\mathrm{CT}$ & 55.3 & 19.0 & 124.2 & 42.8 & 56.5 & 19.5 & 290.5 \\
\hline \multirow{3}{*}{2016} & SM & 76.5 & 22.6 & 137.2 & 40.5 & 48.8 & 14.4 & 338.6 \\
\hline & $\mathrm{BM}$ & 88.5 & $-a$ & 178.1 & - & - & - & - \\
\hline & $\mathrm{CT}$ & 88.7 & 19.3 & 202.7 & 44.1 & 69.6 & 15.1 & 459.9 \\
\hline
\end{tabular}

a The symbol "-_" indicates a lack of data. Due to the malfunction of the soil moisture measuring device under the BM treatment during the fruit maturity stage in 2016, the collected soil moisture data were abnormal. As a result, the ET of the jujube trees during this period and the whole growth period could not be calculated, and therefore, the $\mathrm{CP}$ at each growth stage could not be calculated.

The amount and percentage of water consumption of the experimental rain-fed jujube orchard were significantly different in the different growth stages (Table 2). In the emerging 
and leafing stage, the amount of water consumption of the jujube trees under SM and BM was less than that under CT, which decreased by $4.3-13.7 \%$ and $0.3-3.0 \%$, respectively, in the three experimental years. The water consumption percentage of SM increased by $4.0 \%, 3.4 \%$, and 3.3\% compared to that of CT during the growth periods in 2014, 2015, and 2016, respectively. The percentage of water consumption under BM increased by $1.3 \%$ and $1.6 \%$ in 2014 and 2015, respectively, compared to CT. Similarly to the previous growth stage, during the blossoming and bearing fruit stage, the mulching treatments had the effects of reducing the amount of water consumption and increasing the percentage of water consumption in the three experimental years, of which SM had the most obvious effect. The jujube trees consumed a lot of water during the fruit spreading growth stage, accounting for $30.6-44.1 \%$ of the total water consumption amount during the whole growth period, and the same experimental treatment showed differences in the different precipitation years. In the fruit spreading growth stage in 2014, 2015, and 2016, SM reduced the amount of water consumption by $35.9 \%, 35.3 \%$, and $32.3 \%$, respectively, and reduced the percentage of water consumption by $5.8 \%, 7.8 \%$, and $3.6 \%$, respectively, compared to CT. Compared to $\mathrm{CT}$, the amount of water consumption of BM was reduced by $6.6 \%, 18.1 \%$, and $12.2 \%$ during the fruit spreading growth stage in 2014, 2015, and 2016, respectively. With the advancement of the growth stage, during the fruit maturity stage, the amount of water consumption under SM was reduced by 7.6-34.7\% compared to that under CT in the three experimental years. The water consumption amount of BM was $25.7 \%$ and $2.4 \%$ lower than that of CT in the fruit maturity stage of 2014 and 2015, respectively. SM and BM both had the effect of reducing the percentage of water consumption during the fruit maturity stage in 2014 and 2016. The water consumption percentage under SM and BM increased by $3.3 \%$ and $1.8 \%$, respectively, during the fruit maturity stage in 2015 compared to CT.

\subsection{Soil Moisture Attenuation Characteristics after Typical Rainfall}

Three typical rainfalls were selected in the three experimental years for the study, i.e., one typical rainfall occurred from 8 to 9 July 2014 with a total rainfall of $86.6 \mathrm{~mm}$, another typical rainfall occurred from 9 to 10 September 2015 with a total rainfall of $51.6 \mathrm{~mm}$, and the other typical rainfall occurred from 18 to 19 July 2016 with a total rainfall of $59.2 \mathrm{~mm}$. There was no effective rainfall $(>5 \mathrm{~mm})$ in the two days before and the 11 days after the above three typical rainfalls.

Affected by rainfall and evapotranspiration, the vertical distribution of the soil moisture in the experimental rain-fed jujube orchard under different mulching measures was different (Figure 6). On the first day after the typical rainfall in 2014, the increase in soil moisture in the $0-60 \mathrm{~cm}$ soil layer of the rain-fed jujube orchard under SM, BM, and CT accounted for more than $99.3 \%$ of the total increase in soil moisture (Figure 6A), indicating that this typical rainfall mainly supplemented the soil moisture of the $0-60 \mathrm{~cm}$ soil layer for these three experimental treatments. The typical rainfall in 2015 supplemented the soil moisture of the 0-60, 0-40, and 0-20 cm soil layers for SM, BM, and CT, respectively (Figure 6B). After the typical rainfall in 2016, the increase in soil moisture in the 0-60 cm soil layer under SM and CT and the 0-100 cm soil layer under BM accounted for more than $99.2 \%$ of the total increase in soil moisture (Figure $6 \mathrm{C}$ ).

On the third day after all of the typical rainfalls, the soil moisture of the infiltration layer under all experimental treatments showed attenuation (Figure 6). CT had the maximum soil moisture loss rate, with 9.0\% and 13.2\% in 2014 and 2015, respectively (Figure 6c,f), and SM had the minimum value, with $8.0 \%$ and $4.3 \%$ in 2014 and 2015, respectively (Figure 6a,d). The soil moisture loss rate of the three experimental treatments was $5.5-6.0 \%$ without a significant difference in 2016 (Figure 6C). On the seventh day after typical rainfall, the maximum soil moisture loss rate was obtained by CT, with $23.8 \%, 30.7 \%$, and $19.7 \%$ in 2014, 2015, and 2016, respectively (Figure 6c,f,i). The soil moisture loss rate under BM came second, and that under SM was the lowest, with only $17.1 \%, 8.7 \%$, and $14.3 \%$ in 2014, 2015, and 2016, respectively (Figure 6a,d,g). Compared to the soil moisture loss rate on the third day after a typical rainfall, the soil moisture loss rate on the seventh day 
under CT increased significantly, with the increments all being above $14.2 \%$ in the three experimental years (Figure $6 \mathrm{c}, \mathrm{f}, \mathrm{i}$ ). The soil moisture loss rate under SM increased slowly, especially in 2015, when the increment was only $4.4 \%$ (Figure 6d). With the prolongation of drought after typical rainfall, the soil moisture loss rate of the three experimental treatments continued to increase. On the eleventh day after the typical rainfall, CT still maintained the maximum soil moisture loss rates-all above 37.3\% from 2014 to 2016 (Figure $6 \mathrm{c}, \mathrm{f}, \mathrm{i}$ ). SM still maintained the minimum soil moisture loss rate, which was approximately $24.0 \%$ in 2014 and 2016, and only 14.7\% in 2015 (Figure 6a,d,g). Compared to the soil moisture loss rate on the seventh day after a typical rainfall, the rate of increase of the soil moisture loss rate on the eleventh day after a typical rainfall under CT was significantly higher than that under the mulching treatments, which was above $11.4 \%$ in the three experimental years (Figure $6 \mathrm{c}, \mathrm{f}, \mathrm{i})$, while the rate of increase of the soil moisture loss rate under SM was slow, not exceeding $9.7 \%$ (Figure $6 a, d, g$ ).

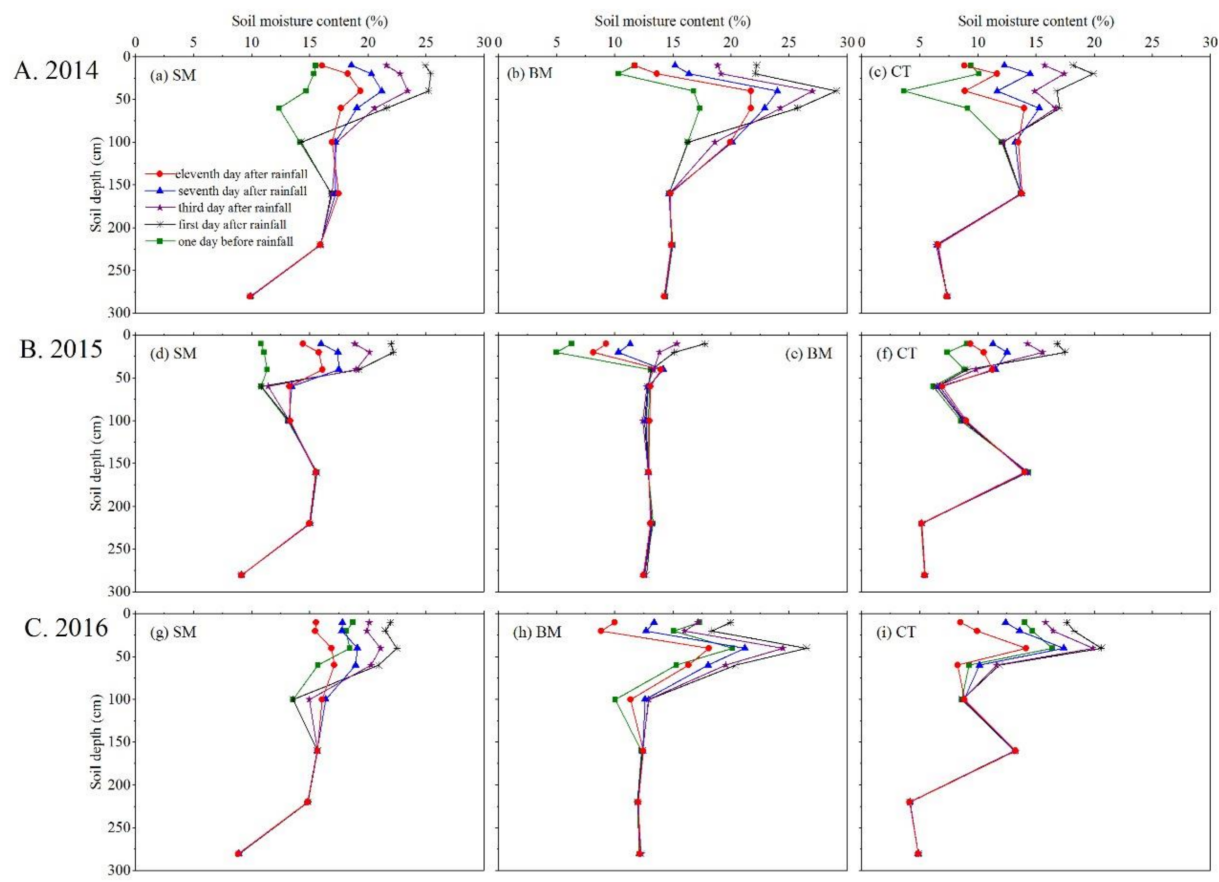

Figure 6. Soil moisture loss over time from the $0-280 \mathrm{~cm}$ profile under different mulching treatments, namely, (a,d,g) SM, (b,e,h) BM, and (c,f,i) CT, after typical rainfall in (A) 2014, (B) 2015, and (C) 2016.

\section{Discussion}

4.1. Soil Moisture Dynamic Changes and Their Attenuation Characteristics after Typical Rainfall in the Rain-Fed Jujube Orchard

Affected by rainfall and evapotranspiration, the soil moisture of the rain-fed jujube orchard in the loess hilly region presented dynamic and hierarchical characteristics in its profile. The soil moisture in the $0-60 \mathrm{~cm}$ soil layer of the jujube orchard fluctuated violently (Figure 4a), which was a seasonal fluctuation layer, mainly because the soil moisture was greatly affected by rainfall and evaporation. The $0-60 \mathrm{~cm}$ soil layer of the rain-fed jujube orchard without mulch had a soil moisture content lower than the wilting moisture and became a low-humidity zone during the fruit spreading growth stage in 2015 and 2016 (Figure 4a). Jujube trees are very sensitive to moisture in the fruit spreading growth stage [29], and a lack of soil moisture during this period will significantly affect fruit expansion, resulting in lower yield and fruit deformity. The soil moisture in the $60-160 \mathrm{~cm}$ soil layer was less affected by rainfall (Figure $4 \mathrm{~b}$ ), and the soil moisture in the $160-280 \mathrm{~cm}$ soil layer was hardly affected by rainfall (Figure 4c). The 160-280 cm soil layer under CT formed a perennial low humidity zone in the three experimental years (Figure 4c), indicating that the rain-fed jujube orchard did not form a soil reservoir that can regulate 
jujube growth under natural rainfall. Once entering a dry year, the jujube growth is bound to be adversely affected.

As the drought continued after a typical rainfall, the rain-fed jujube orchard covered with straw and jujube branches had a lower soil moisture loss rate than under the CT treatment (Figure 6). The reason may be that the covering materials used can effectively block solar radiation, weaken the gas exchange between the soil and the air, reduce the heat supply to the soil moisture evaporation process, greatly reduce the surface soil temperature, and hinder the soil moisture evaporation, thereby playing a role in soil moisture conservation, which is conducive to soil water storage [30,31].

\subsection{Suggestions for Soil Moisture Management in Rain-Fed Jujube Orchards}

Soil moisture is a key factor that determines the success or failure of artificial afforestation in the loess hilly region. Unreasonable afforestation is likely to cause soil drought, restrict the growth of artificial forests, and lead to a decline in artificial forests [32,33]. The results showed that both straw mulching and jujube branch mulching could well enhance soil water storage capacity (Figure 5), reduce the amount of water consumption during the whole growth period (Table 2), and improve the soil moisture environment in the rain-fed jujube orchard, which is consistent with previous research results [34,35]. In this study, straw mulching was better than jujube branch mulching in improving the soil moisture environment in the rain-fed jujube orchard. Although jujube branch mulching can also intercept rainwater, store water, and reduce soil moisture evaporation, the number of branches pruned from jujube trees is extremely limited, making it difficult to meet the demand for the large-scale coverage of jujube orchards. The reason why straw mulching has a better moisture retention effect may be that the supply of straw is sufficient, which can minimize ineffective soil evaporation. In addition, compared to jujube branches, straw has a larger specific surface area, which affords it a strong adsorption capacity for rainfall and water vapor [36], and straw has a lower porosity, which blocks the direct water connection between the soil surface and the atmosphere, weakens the convection exchange between the air in the soil and the atmosphere, and inhibits soil evaporation, thus improving the soil moisture content, showing a good performance in soil moisture conservation [37]. The improvement of a soil moisture environment plays an important role in the growth of rain-fed jujube trees. Therefore, it is recommended to use straw mulching in rain-fed jujube orchards in the loess hilly region to ensure the efficient use of natural precipitation and the healthy and sustainable development of jujube orchards. Compared to bare soil without mulching, jujube branch mulching also has a good moisture retention effect. If the pruned jujube branches are discarded and burned, this not only pollutes the environment but also increases transportation costs. Thus, if jujube branches and straw are combined to cover the soil surface of a rain-fed jujube orchard, whether it can achieve a good moisture preservation effect is a topic worthy of study.

\section{Conclusions}

(1) The 0-60 cm soil layer of the rain-fed jujube orchard was the seasonal fluctuation layer of the soil moisture under straw mulching (SM), jujube branch mulching (BM), and clean tillage (CT) in both the normal precipitation years and the dry year. The 0-60, 60-160, and 160-280 cm soil layers under CT all obtained the lowest soil moisture content in the three experimental years, and the $160-280 \mathrm{~cm}$ soil layer formed a perennial low-humidity zone. The soil moisture content of each soil layer under SM and BM was higher than that under CT, and SM had the most obvious effect of improving soil moisture.

(2) SM and BM showed significant soil water storage effects in all of the jujube growth stages in both the normal precipitation years and the dry year, and SM had a better water storage effect than BM.

(3) $\mathrm{SM}$ and $\mathrm{BM}$ reduced the amount of water consumption in each jujube growth stage. $\mathrm{SM}$ and $\mathrm{BM}$ increased the water consumption percentage in the emerging, leafing, 
blossoming and bearing fruit stages in the three experimental years. SM reduced the percentage of water consumption in the fruit spreading growth stage. During the fruit maturity stages in the normal precipitation years, SM and BM both reduced the water consumption percentage, while in the dry year, they increased the percentage of water consumption. The effect of SM on the amount and percentage of water consumption was more obvious than that of BM.

(4) The soil moisture loss rate of CT was significantly higher than that of SM and BM under continuous drought after rainfall. With the extension of drought, the soil moisture loss rate under SM increased slowly, while it increased rapidly under CT.

In conclusion, it is recommended to adopt mulching measures in rain-fed jujube orchards in the loess hilly region to ensure the efficient utilization of precipitation and the sustainable development of said jujube orchards. Straw mulching is the best mulching measure, while pruned jujube branches can also cover a rain-fed jujube orchard in situ, which can achieve a certain moisture conservation effect.

Author Contributions: Conceptualization, M.T., X.Z. and P.W.; methodology, M.T.; formal analysis, M.T.; investigation, M.T. and H.L.; resources, X.Z. and P.W.; data curation, M.T. and H.L.; writingoriginal draft preparation, M.T.; writing—review and editing, C.Z. and X.G.; visualization, M.T.; supervision, X.Z. and P.W.; project administration, X.G.; funding acquisition, C.Z., X.Z. and P.W. All authors have read and agreed to the published version of the manuscript.

Funding: This research was funded by the National Natural Science Foundation of China (No. 51909228, 51579212, and 41571506) and the National Key Research and Development Program of China (No. 2016YFC0400204).

Institutional Review Board Statement: Not applicable.

Informed Consent Statement: Not applicable.

Data Availability Statement: Data sharing not applicable.

Acknowledgments: The authors are grateful to Qiang Ling and Lusheng Li for their kind help in the installation of experimental equipment and data acquisition.

Conflicts of Interest: The authors declare no conflict of interest.

\section{References}

1. Yang, L.; Zhang, H.; Chen, L. Identification on threshold and efficiency of rainfall replenishment to soil water in semi-arid loess hilly areas. Sci. China Earth Sci. 2018, 61, 292-301. [CrossRef]

2. Feng, J.; Wei, W.; Pan, D. Effects of rainfall and terracing-vegetation combinations on water erosion in a loess hilly area, China. J. Environ. Manag. 2020, 261, 110247. [CrossRef] [PubMed]

3. Song, L.; Liu, W.; Wu, H.; Gao, T.; Hao, W. Characteristics of soil nutrients and their relationship with soil microbial properties in Artemisia sacrorum communities in the loess hilly region. Int. J. Agric. Biol. Eng. 2018, 11, 127-134. [CrossRef]

4. Yang, K.; Lu, C. Evaluation of land-use change effects on runoff and soil erosion of a hilly basin-The Yanhe River in the Chinese loess plateau. Land Degrad. Dev. 2018, 29, 1211-1221. [CrossRef]

5. Qin, Y.; Xin, Z.; Yu, X.; Xiao, Y. Influence of vegetation restoration on topsoil organic carbon in a small catchment of the loess hilly region, China. PLoS ONE 2014, 9, e94489. [CrossRef]

6. Gao, Z.; Shi, W.; Wang, X.; Wang, Y. Non-rainfall water contributions to dryland jujube plantation evapotranspiration in the Hilly Loess Region of China. J. Hydrol. 2020, 583, 124604.

7. Jin, S.; Wang, Y.; Shi, L.; Guo, X.; Zhang, J. Effects of pruning and mulching measures on annual soil moisture, yield, and water use efficiency in jujube (Ziziphus jujube Mill.) plantations. Glob. Ecol. Conserv. 2018, 15, e00406.

8. Chen, D.; Wang, Y.; Liu, S.; Wei, X.; Wang, X. Response of relative sap flow to meteorological factors under different soil moisture conditions in rainfed jujube (Ziziphus jujuba Mill.) plantations in semiarid Northwest China. Agric. Water Manag. 2014, 136, 23-33. [CrossRef]

9. Ling, Q.; Gao, X.; Zhao, X.; Huang, J.; Li, H.; Li, L.; Sun, W.; Wu, P. Soil water effects of agroforestry in rainfed jujube (Ziziphus jujube Mill.) orchards on loess hillslopes in Northwest China. Agric. Ecosyst. Environ. 2017, 247, 343-351. [CrossRef]

10. Huang, J.; Wang, J.; Zhao, X.; Li, H.; Jing, Z.; Gao, X.; Chen, X.; Wu, P. Simulation study of the impact of permanent groundcover on soil and water changes in jujube orchards on sloping ground. Land Degrad. Dev. 2016, 27, 946-954.

11. Pearson, C.H.; Holcomb, C.A.; Cooley, A.W.; Murray, J.E. Guidelines for Using Conservation Tillage under Furrow Irrigation; Technical Report Colorado Agricultural Experiment Station, Fruita Research Center: Fruita, CO, USA, 2002; p. TR02-6. 
12. Wasaya, A.; Yasir, T.A.; Ijaz, M.; Ahmad, S. Agronomic Crops; Springer: Singapore, 2019; pp. 73-99.

13. Mikha, M.M.; Benjamin, J.G.; Vigil, M.F.; Poss, D.J. Manure and tillage use in remediation of eroded land and impacts on soil chemical properties. PLOS ONE 2017, 12, e0175533.

14. Kader, M.A.; Senge, M.; Mojid, M.A.; Onishi, T.; Ito, K. Effects of plastic-hole mulching on effective rainfall and readily available soil moisture under soybean (Glycine max) cultivation. Paddy Water Environ. 2017, 15, 659-668. [CrossRef]

15. Jafari, M.; Haghighi, J.A.P.; Zare, H. Mulching impact on plant growth and production of rainfed fig orchards under drought conditions. J. Food Agric. Environ. 2012, 10, 428-433.

16. Adak, T.; Kumar, K.; Singha, A.; Shukla, S.K.; Singh, V.K. Assessing soil characteristics and guava orchard productivity as influenced by organic and inorganic substrates. J. Anim. Plant Sci. 2014, 24, 1157-1165.

17. Sofo, A.; Ciarfaglia, A.; Scopa, A.; Camele, I.; Curci, M.; Crecchio, C.; Xiloyannis, C.; Palese, A.M. Soil microbial diversity and activity in a Mediterranean olive orchard using sustainable agricultural practices. Soil Use Manag. 2014, 30, $160-167$.

18. Lordan Sanahuja, J.; Pascual Roca, M.; Villar Mir, J.M.; Fonseca Salcedo, F.; Papió, J.; Montilla, V.; Rufat i Lamarca, J. Use of organic mulch to enhance water-use efficiency and peach production under limiting soil conditions in a three-year-old orchard. Span. J. Agric. Res. 2015, 13, e0904. [CrossRef]

19. Almagro, M.; Garcia-Franco, N.; Martínez-Mena, M. The potential of reducing tillage frequency and incorporating plant residues as a strategy for climate change mitigation in semiarid Mediterranean agroecosystems. Agric. Ecosyst. Environ. 2017, 246, 210-220.

20. Joolka, N.K.; Chand, R.; Sharma, S. Impact of water conservation techniques and herbicidal treatments on yield and quality of Delicious apple under water stress conditions. Indian J. Hortic. 2008, 65, 12-15.

21. Ojasvi, P.R.; Goyal, R.K.; Gupta, J.P. The micro-catchment water harvesting technique for the plantation of jujube (Zizyphus mauritiana) in an agroforestry system under arid conditions. Agric. Water Manag. 1999, 41, $139-147$.

22. Hao, M.; Wei, X.; Dang, T. Effect of long-term applying zinc fertilizer on wheat yield and content of zinc in dryland. Plant Nutr. Fertil. Sci. 2003, 9, 377-380. (in Chinese with English abstract)

23. Li, L.; Gao, X.; Wu, P.; Zhao, X.; Li, H.; Ling, Q.; Sun, W. Soil water content and root patterns in a rain-fed jujube plantation across stand ages on the loess plateau of China. Land Degrad. Dev. 2017, 28, 207-216. [CrossRef]

24. Akhtar, K.; Wang, W.; Khan, A.; Ren, G.; Afridi, M.Z.; Feng, Y.; Yang, G. Wheat straw mulching with fertilizer nitrogen: An approach for improving soil water storage and maize crop productivity. Plant Soil Environ. 2018, 64, $330-337$.

25. Ritchie, J.T. A user-orientated model of the soil water balance in wheat. In Wheat Growth and Modelling; Day, W., Atkin, R.K., Eds.; Springer: Boston, MA, USA, 1985; pp. 293-305.

26. Han, S.; Li, Y.; Zhang, X.; Shi, Z. The regional dynamic characteristics of soil water on the Loess Plateau. Res. Soil Water Conserv. 1989, 1, 161-167, (in Chinese with English abstract).

27. Huang, L.; Gao, Y.; Qiu, X.; Li, X.; Shen, X.; Sun, J.; Gong, W.; Duan, A. Effects of irrigation amount and stage on yield and water consumption of different winter wheat cultivars. Trans. Chin. Soc. Agric. Eng. 2013, 29, 99-108. (in Chinese with English abstract)

28. Huang, Z.; Cao, Y.; Ouyang, Z.; Tu, N.; Zheng, H. Dynamics of soil water under Vernicia fordii plantation in hilly red soil region of Southern China. Chin. J. Appl. Ecol. 2007, 18, 241-246.

29. Ma, Y.; Zheng, G.; Zhou, J.; Zheng, Q. Effects of different irrigation thresholds on the growth and water use efficiency of jujube trees. Agric. Res. Arid Areas 2020, 38, 58-61. (in Chinese with English abstract)

30. Zribi, W.; Aragüés, R.; Medina, E.; Faci, J.M. Efficiency of inorganic and organic mulching materials for soil evaporation control. Soil Tillage Res. 2015, 148, 40-45. [CrossRef]

31. Saglam, M.; Sintim, H.Y.; Bary, A.I.; Miles, C.A.; Ghimire, S.; Inglis, D.A.; Flury, M. Modeling the effect of biodegradable paper and plastic mulch on soil moisture dynamics. Agric. Water Manag. 2017, 193, 240-250. [CrossRef]

32. Srivastava, R.J.; Kumar, A.; Prasad, K. Studies on soil moisture variations under eucalyptus plantation. Studies 2003, 500, B2.

33. Berthrong, S.T.; Jobbágy, E.G.; Jackson, R.B. A global meta-analysis of soil exchangeable cations, pH, carbon, and nitrogen with afforestation. Ecol. Appl. 2009, 19, 2228-2241.

34. Pan, D.; Zhao, X.; Gao, X.; Song, Y.; Dyck, M.; Wu, P.; Li, Y.; Ma, L. Application rate influences the soil and water conservation effectiveness of mulching with chipped branches. Soil Sci. Soc. Am. J. 2018, 82, 447-454.

35. Wang, X.; Gao, Z.; Wang, Y.; Nie, Z.; Jin, S.; Dong, J. Effects of pruning and mulching on soil desiccation remediation in rain-fed jujube plantation in the semi-arid loess hilly gull region. Sci. Silvae Sin. 2018, 54, 24-30. (in Chinese with English abstract)

36. Blanco-Canqui, H.; Lal, R. Impacts of long-term wheat straw management on soil hydraulic properties under no-tillage. Soil Sci. Soc. Am. J. 2007, 71, 1166-1173. [CrossRef]

37. Gholami, L.; Banasik, K.; Sadeghi, S.H.; Darvishan, A.K.; Hejduk, L. Effectiveness of straw mulch on infiltration, splash erosion, runoff and sediment in laboratory conditions. J. Water Land Dev. 2014, 22, 51-60. [CrossRef] 